\title{
Laparoscopic Reversal of Hartmann's Procedure: A Single Surgeon Experience
}

Bourguiba Mohamed Aboulkacem ${ }^{1 *}$, Ghalleb Montassar ${ }^{2}$, Baccari Aymen ${ }^{2}$, Souai Faten $^{2}$, Ben Safta Yacine $^{2}$, Sayari Sofiene $^{2}$ and $B e n_{\text {Moussa Mounir }}^{2}$

${ }^{1}$ Faculty of Medecine of Tunis, University of Tunis El Manar, Tunisia

${ }^{2}$ General Surgery Department, Charles Nicolle Hospital, Tunisia

*Corresponding author: Bourguiba Mohamed Aboulkacem, Faculty of Medecine of Tunis, University of Tunis El Manar, Tunisia, Tel: (+216)52555278; Email: belgacembourguiba@yahoo.fr

Received date: June 30, 2017; Accepted date: July 01, 2017; Published date: July 05, 2017

Copyright: () 2017 Bourguiba MA. This is an open access article distributed under the terms of the Creative Commons Attribution License, which permits unrestricted use, distribution, and reproduction in any medium, provided the original author and source are credited.

\begin{abstract}
Introduction: The laparoscopic reversal Hartmann procedure is a challenging technique showing promising results in comparison to the open procedure.

Aim: Report a single surgeon experience showing promising results.

Results: It's a twelve patient's case series. The median age was 62 years old. The mean operative time was $148.16 \mathrm{~min}$ (75-210 $\mathrm{min})$. No per-operative complication was reported. Only one procedure was converted to laparotomy due to severe pelvic adhesions. All patients ambulated on postoperative day 1 . The Mean time to the recovery of the bowel movement was Two days (1 to 4 days). The mean time to Oral analgesia intake was 1.66 days (1 to 3). The mean time of hospital stay was 5.66 Days (4 to 8 ). Two patients had complication in a mean time of 18 days after the surgery.
\end{abstract}

Conclusion: The laparoscopic reversal Hartmann procedure is a safe technique showing promising results but in the hand of trained laparoscopic surgeon.

Keywords: Surgery; Laparoscopy; Hartmann's procedure

\section{Introduction}

The Hartmann's procedure (HP) is a surgical technique first described in 1921 to treat rectal cancer [1]. The initial technique never considered the restoration of the intestinal tract continuity. Through time the technique has seen some changes; Boyden et al. showed late results with the closure of the colostomy [2]. Anderson et al. were the first to describe a laparoscopically assisted colostomy closure [3]. Since; many surgeons have tried the Laparoscopic Reversal of Hartmann's Procedure (RHP) with rather good results [4]. However it's not a standard of care and many surgeons prefer the conventional laparotomy approach. Our aim is to report a single surgeon experience showing promising results.

\section{Methods}

\section{Patients' selection}

A case series of 12 patients undergoing Laparoscopic RHP from January 2014 to December 2015 in the surgery department of Charles Nicolle hospital was done.

All the patients who had HP by the same surgeon with no regards to the etiology or the initial way of entry were included. The patients with malignant disease have been operated in emergency setting so none had preoperative chemo radiation and none was locally advanced. The RHP were also made by the same surgeon as stated in Table 1 .
The first step of the technique involves mobilization of the colostomy site. This is excised circumferentially, until the peritoneum is entered. The edge of the stoma is revised to take away excessive scar tissue. An anvil of a circular stapler is then inserted into the colonic lumen and secured with a purse-string suture. The colostomy site is then used as port site for the establishment of pneumoperitoneum and a trocar can be placed for the camera. Three operative trocars are used: a $5 \mathrm{~mm}$ trocar in the right lower quadrant, a $5 \mathrm{~mm}$ in the right upper quadrant and a $10 \mathrm{~mm}$ in the umbilicus. With the patient in a steep Trendelenburg position, the rectal stump is identified. After Lysis of Adhesions were performed with sharp scissor dissection. An end-toend colorectal anastomosis is created with an appropriately sized endoluminal circular stapler; the pelvic cavity is filled with saline solution and the air leak test is done by insufflating the air in the rectum while visualizing the anastomosis. Post-operatively, the patients had multimodal analgesia based on paracetamol and non-steroidal anti-inflammatory drugs. Food allowance was after first flatus.

\section{Results}

\section{Patient's characteristics}

The median age was 62 years old (45 to 80 ). The sex ratio is $1 / 1$. Only one patient was operated in scheduled surgery but had a HP due to poor colonic pre-operative preparation. The most common etiology was pelvic colon Volvulus (six cases). For the patients with malignant disease all of them have been operated in emergency setting so none had preoperative chemo radiation and in the final histologic examination all were pT3 (Table 1). 
Citation: Bourguiba MA, Ghalleb M, Baccari A, Souai F, Ben Safta Y, et al. (2017) Laparoscopic Reversal of Hartmann's Procedure: A Single Surgeon Experience. J Gen Pract (Los Angel) 5: 314. doi:10.4172/2329-9126.1000314

Page 2 of 3

\begin{tabular}{|c|c|c|c|c|c|}
\hline Patients & Sex & Age (Years) & Etiology & Way of entry & Emergency Setting \\
\hline 1 & M & 66 & Volvulus & Vertical midline & YES \\
\hline 2 & M & 80 & Volvulus & Vertical midline & YES \\
\hline 3 & M & 58 & Volvulus & Vertical midline & YES \\
\hline 4 & M & 50 & Sigmoide tumor in occlusion & Vertical midline & YES \\
\hline 5 & $\mathrm{~F}$ & 70 & Sigmoide tumor (poorly prepared patient) & Open Laparoscopy & NO \\
\hline 6 & $\mathrm{~F}$ & 70 & Volvulus & Vertical midline & YES \\
\hline 7 & $\mathrm{~F}$ & 62 & Sigmoide tumor in occlusion & Vertical midline & YES \\
\hline 8 & $\mathrm{~F}$ & 45 & Sigmoide tumor with perforation & Vertical midline & YES \\
\hline 9 & $\mathrm{~F}$ & 66 & Crohn's disease Acute colitis & Vertical midline & YES \\
\hline 10 & M & 75 & Volvulus & Laparoscopy & YES \\
\hline 11 & M & 54 & Sigmoide tumor in occlusion & Vertical midline & YES \\
\hline 12 & $\mathrm{~F}$ & 46 & Sigmoide tumor in occlusion & Vertical Midline & YES \\
\hline
\end{tabular}

Table 1: Patient's characteristics.

\section{Operative data}

The mean operative time was $148.16 \mathrm{~min}(75-210 \mathrm{~min})$. No peroperative complications were reported. Only one procedure was converted to laparotomy due to severe pelvic adhesions (Table 2).

\begin{tabular}{|c|c|c|c|c|c|c|}
\hline Patients & $\begin{array}{l}\text { Procedure } \\
\text { time } \\
\text { (min) }\end{array}$ & Conversion & $\begin{array}{l}\text { Recovery of bowel } \\
\text { motility }\end{array}$ & Complications & IV analgesia & Hospital Stay(Day) \\
\hline 1 & 168 & 0 & D2 & 0 & D1 post op & 5 \\
\hline 2 & 160 & 0 & $\mathrm{D} 2$ & 0 & D1 post op & 4 \\
\hline 3 & 190 & 0 & D1 & 0 & D2 post op & 6 \\
\hline 4 & 175 & 0 & D2 & Pelvic infected Hematoma & D2 post op & 8 \\
\hline 5 & 210 & (1) difficult adhesion lysis & D3 & 0 & D2 post op & 7 \\
\hline 6 & 150 & 0 & D4 & 0 & D2 post op & 6 \\
\hline 7 & 145 & 0 & D3 & 0 & D1 Post op & 7 \\
\hline 8 & 135 & 0 & D3 & 0 & D3 post op & 7 \\
\hline 9 & 75 & 0 & D2 & 0 & D1 post op & 5 \\
\hline 10 & 90 & 0 & D1 & 0 & D1 post op & 4 \\
\hline 11 & 120 & 0 & $\mathrm{D} 2$ & Pelvic Abcess & D2 post op & 4 \\
\hline 12 & 160 & 0 & D1 & 0 & D2 post op & 5 \\
\hline Ratio/median & 148,16 & 01-Dec & 2 & 02-Dec & 1,66 & 5,66 \\
\hline
\end{tabular}

Table 2: Operative and post-operative data. 


\section{Discussion}

When surgical procedure is indicated, the immediate intestinal continuity is used more and more [4]. The only indication, as a gold standard for HP, remains the stercoral peritonitis due to a sigmoid perforation [5]. Approximately $44 \%$ of patients undergo bowel continuity restoration after HP [6]. As shown by Van de Wall review of the literature Reversal of HP is accompanied by a considerable risk of complications (mean 16.3\%, range $3 \%-50 \%$ ) and has an overall mortality rate of $1 \%$. Overall complication rates reported in series of open Hartmann's reversal range from 4\%-43\%, Anastomotic Leakage occurring in up to $12 \%$ of patients [7]. Thus, many surgical teams thought of different ways to reduce this morbidity. One of them was the use of laparoscopy and its known advantages on open procedure to re-establish the intestinal continuity have been well demonstrated in the last twenty years [4]. Rapid postoperative recovery, less postoperative pain, earlier Ambulation, earlier restoration of bowel function, a more rapid return to a normal diet, and Reduced morbidity are the major advantages of this technique [6]. However, two main challenges faced by the laparoscopic approach: A safe laparoscopic entry in a previously operated abdomen and the severe intraabdominal adhesions.

Regarding the way of entry; many authors have used the umbilical Hasson technique [8-10]. This method allows the exploration of the abdominal cavity, assessment of the feasibility of laparoscopy and adhesiolysis; with dissection of the colostomy under direct vision [4]. In our case series, we started with dissection of the Colostomy and used the incision as the way of the entry a purse-string suture on the aponevrotic wall was used to reduce Gas leakage. Some other authors used the palmer point as entry technique and it was also considered as a safe way of entry [11]. The adhesions are the main cause of conversion to the open technique during laparoscopic reversal procedure $[4,6]$. In our case series; the only case of conversion was due to severe adhesions. Regarding intraoperative Data, in open Hartmann's procedure, the mean operative time reported in literature is $167 \mathrm{~min}$ [12]. In laparoscopic Hartmann's procedure, the mean operative time was $171.1 \mathrm{~min}$ [4]. In our work the Mean operative time was $148.12 \mathrm{~min}$ a slight shorter than the literature. This can be explained by the careful selection of patients and the choice of an experimented laparoscopic surgeon.

Many authors report less intraoperative blood loss, shorter hospital stay, less wound infection rate, less postoperative pain $[13,14]$. The patient's convalescence, the first ambulation, and oral feeding are achieved faster [15]. In Toro et al. review, the mean length of hospital stay was 6.2 days [4]. Laparoscopic reversal has shown less morbidity and mortality in relation to open Hartmann's reversal procedure. The morbidity with open Hartmann's reversal is reported at 4\%-43\% [13], and the mortality rate ranges from $4 \%-10 \%$ [15]. In Toro et al. review, morbidity was $15.8 \%$ and the mortality was $0.7 \%$ [12]. In our study two patients had post-operative complications and one of them needed to be re-operated.

\section{Conclusion}

The laparoscopic RHP is safer and achieves faster positive results in comparison to the open RHP in the hand of Good and trained laparoscopic surgeon and in carefully selected patients.

\section{Ethics Approval and Consent to Participate}

Written informed consent was obtained from the patients for publication of this case report and any accompanying images. A copy of the written consent is available for review by the Editor-in-Chief of this journal.

We declare no conflicts of interest between the author and that this work was made with all the due respect to the code of ethics under the supervision of the medical and ethic committee of the Charles Nicolle Hospital.

\section{References}

1. Hartmann H (1921) Chirurgie du Rectum, Masson, Paris, France.

2. Boyden AM (1950) The surgical treatment of diverticulitis of the colon. Ann Surg 132: 94-109.

3. Anderson CA, Fowler DL, White S, Wintz N (1993) Laparoscopic colostomy closure. Surg Laparosc Endosc 3: 69-72.

4. Toro A, Ardiri A, Mannino M, Politi A, Di Stefano A, et al. (2014) Laparoscopic reversal of Hartmann's procedure: State of the art 20 years after the first reported case. Gastroenterol Res Pract: 530140.

5. Carus T, Bollmann S, Lienhard H (2008) Laparoscopic reversal of Hartmann's procedure: Technique and results. Surg Laparosc Endosc Percutan Tech 18: 24-28.

6. van de Wall BJM, Draaisma WA, Schouten ES, Broeders IAMJ, Consten ECJ (2010) Conventional and laparoscopic reversal of the Hartmann procedure: A review of literature. J Gastrointest Surg 14: 743-752.

7. Vermeulen J, Coene PPLO, Van Hout NM, van der Harst E, Gosselink MP, et al. (2009) Restoration of bowel continuity after surgery for acute perforated diverticulitis: Should Hartmann's procedure be considered a one-stage procedure? Colorectal Dis 11: 619-624.

8. Caselli G, Bambs C, Pinedo G, Molina ME, Zúñiga A, et al. (2010) Laparoscopic approach for intestinal passage reconstruction after Hartmann's operation: Experience with 30 patients. Cir Esp 88: 314-318.

9. Chouillard E, Pierard T, Campbell R, Tabary N (2009) Laparoscopically assisted Hartman's reversal is an efficacious and efficient procedure: A case control study. Minerva Chirurgica 64: 1-8.

10. Agaba EA, Zaidi RM, Ramzy P, Aftab M, Rubach E, et al. (2009) Laparoscopic Hartmann's procedure: A viable option for treatment of acutely perforated diverticultis. Surg Endosc 23: 1483-1486.

11. Rosen MJ, Cobb WS, Kercher KW, Sing RF, Heniford BT (2005) Laparoscopic restoration of intestinal continuity after Hartmann's procedure. Am J Surg 189: 670-674.

12. Okolica D, Bishawi M, Karas JR, Reed JF, Hussain F, et al. (2012) Factors influencing postoperative adverse events after Hartmann's reversal: Hartmann's reversal timing. Colorectal Dis 14: 369-373.

13. Mazeh H, Greenstein AJ, Swedish K, Nguyen SQ, Lipskar A, et al. (2009) Laparoscopic and open reversal of Hartmann's procedure: A comparative retrospective analysis. Surg Endosc 23: 496-502.

14. de'Angelis N, Brunetti F, Memeo R, Batista da Costa J, Schneck AS, et al. (2013) Comparison between open and laparoscopic reversal of Hartmann's procedure for diverticulitis. World J Gastrointest Surg 5: 245-251.

15. Golash V (2006) Laparoscopic reversal of Hartmann procedure. J Min Access Surg 2: 211-215. 